\title{
Svetovna primerjalna književnost
}

\author{
David Damrosch: Comparing the Literatures. Literary Studies in a Global
} Age. Princeton, NJ: Princeton University Press, 2020. 386 str.

\section{Blaž Zabel}

Filozofska fakulteta, Univerza v Ljubljani, Oddelek za filozofijo, Aškerčeva 2, 1000 Ljubljana https://orcid.org/0000-0001-6512-1565

blaz.zabel@ff.uni-li.si

Naslov te recenzije, "Svetovna primerjalna književnost" se morda zdi nenavaden. Vemo, kaj je to "primerjalna književnost ", literarnovedna disciplina, ki jo včasih imenujemo tudi komparativistika. Prav tako si lahko vsaj nekako predstavljamo, kaj je to "svetovna književnost«, pa čeprav je bilo o tem v zadnjih dvajsetih letih prelito že mnogo črnila. A "svetovna primerjalna književnost", kaj je to? $S$ tem vprašanjem se v svoji najnovejši monografiji z naslovom Comparing the Literatures: Literary Studies in a Global Age ukvarja David Damrosch, profesor primerjalne književnosti na Univerzi Harvard. Povedano drugače, v študiji, ki je nedavno izšla pri Princeton University Press, se eden najslavnejših komparativistov enaindvajsetega stoletja sprašuje o vlogi primerjalne književnost $\mathrm{v}$ času globalizacije, to pa na način, da razpravlja o zgodovini komparativistike ter o zgodovini primerjalnih metod $\mathrm{v}$ literarni vedi. Pri tem se posebej osredotoča na tiste zgodovinske vidike, ki so jih raziskovalci v zadnji dveh desetletjih izpostavili kot bistvene za razumevanje transnacionalizacije ter globalizacije, kot so na primer medkulturni vplivi, vznik postkolonialnih študij, razvoj prevodoslovja, svetovni obtok idej itd.

Da se je Damrosch odločil preučiti »razvoj literarnih ved v dobi globalizacije«, ni povsem nepričakovano. Damrosch je namreč tako pri nas kot po svetu najbolj znan po svoji odmevni študiji What is World Literature? (2003), v kateri se je ukvarjal predvsem s književnostjo v dobi globalizacije, medkulturno in transhistorično recepcijo literarnih del ter s prevodoslovjem. Če se je torej v monografiji s preloma tisočletja, ki je v komparativistiki sprožila pravo revolucijo, ukvarjal predvsem z vprašanjem svetovne književnosti, pa lahko njegovo najnovejše delo razumem kot nadaljevanje, le da se tokrat namesto na samo književnost osredotoči na vedo, ki svetovno književnost preučuje, torej na "svetovno primerjalno književnost«. A glavna teza njegove najnovejše raziskave je podobna: tako kot je $\mathrm{v}$ globaliziranem svetu potrebno razmišljati o svetovni književnosti (torej o literarnih delih, ki 
predvsem v obliki prevodov potujejo preko svojih lokalnih okvirov in bralce seznanjajo z drugačnimi svetovi), tako je tudi o komparativistiki nujno razmišljati z vidika transnacionalizacije. Tudi akademske ideje namreč potujejo med različnimi kulturnimi konteksti, raziskovalci razmišljajo o prevodih, o perifernih ali ne-kanoniziranih literarnih delih, se soočajo z vprašanji in pritiski globalizacije, vse to pa vpliva na pojav in razvoj komparativistike kot literarnovedne discipline. Rezultat te raziskave, Comparing the Literatures je odličen pregled razvoja komparativistike, ki ponuja povsem svež pogled na preteklost te vede, preko raziskovanja njene preteklosti pa avtor oblikuje tudi svoj odgovor na sodobne raziskovalne izzive.

V prvem poglavju se David Damrosch posveti zgodnjim začetkom primerjalne književnosti. Za razliko od What is World Literature?, ki v uvodu obravnava idejo Weltliteratur Johanna Wolfganga von Goetheja, se Comparing the Literatures začne z njegovim antagonistom Johannom Gottfriedom Herderjem. Avtor razpravlja o različnih vidikih nacionalne in primerjalne književnosti, ki jih je zagovarjal romantični mislec, hkrati pa ponuja svežo tezo o produktivnosti vpliva sočasnih francoskih akademikov (ki predstavlja zanimiv antipod ideji Isaiah Berlina o antirazsvetljenstvu). Prav s tem namenom Damrosch v poglavju obravnava še Madame de Staël, ki prav tako predstavlja eno izmed utemeljiteljic komparativistike, posveti pa se njenemu razmišljanju o odnosu med literaturo in družbenimi institucijami. Ker je prvo poglavje namenjeno začetkom primerjalne književnosti, avtor monografije seveda ne more mimo Huga Meltzla in Hutchesona Maucalaya Posnetta, pri čemer prvemu pripiše začetek zavezanosti naše vede poliglotizmu, drugemu pa idejo estetske relativnosti. Prvo poglavje je tako odličen uvod v nekaj najpomembnejših in najprepoznavnejših začetkov komparativistike, a posebna dodana vrednost razprave je sinteza najnovejših ugotovitev in tez o delu teh zgodnjih komparativistov.

Če se prvo poglavje ukvarja predvsem z izvori primerjalne književnosti (torej 18. in 19. stoletjem), so preostala poglavja monografije posvečena različnim tematskim vprašanjem. Drugo poglavje tako obravnava akademske migrante, ki veljajo za ustanovitelje ameriške komparativistike. Poseben doprinos tega dela razprave je Damroschev ne-evropocentričen pogled na to tematiko: čeprav v svojem delu obravnava tudi najbolj znana povojna imigranta $\mathrm{v}$ primerjalni književnosti, Lea Spitzerja in Ericha Auerbacha (kjer ponuja izvrstno sintezo najnovejših in preštevilnih razprav), pa enakovredno pozornost nameni tudi delu dveh kitajskih (i)migrantov, Hu Shih (znan jezikovni revolucionar, ki se je šolal na univerzi Cornell) in Lin Yutang (kitajski pisatelj 
ter odmeven prevajalec), pa tudi delu komparativistke Lilian Furst, ki jo je zaznamovala izkušnja pobega pred nacizmom. Prav marginalnost Auerbacha in Spitzerja, dveh "velikanov « komparativistike, ponuja svež in inovativen pogled na zgodovino discipline, ki so jo $\mathrm{v}$ mnogih pogledih še bolj kot "velikani« zaznamovale tudi druge kulture in pozabljene komparativistke.

V tretjem poglavju se Damrosch posveti vprašanju ameriške komparativistike po drugi svetovni vojni, ki se ga loti s politično-historičnega vidika, ter vprašanju političnosti literarnih ved. Najprej razpravlja o komparativistiki v petdesetih in šestdesetih letih, ki jo je močno zaznamovala hladna vojna (Balakian, Welek, Frye, Greene), a zanimivejši del razprave predstavlja drugi del poglavja, ki obravnava delo Edwarda Saida ter Gayatri Spivak. V obeh primerih avtor postreže z zanimivo interpretacijo njune postkolonialne teorije $\mathrm{v}$ kontekstu sočasnih političnih dogajanj (predvsem v Palestini) in kulturnih vojn v akademskem prostoru. Cetrto poglavje obravnava obdobje prevlade literarne teorije v ameriški komparativistiki, predvsem dekonstrukcije Paula de Mana in Barbare Johnson, pri čemer Damroscha še posebej zanimajo nedavno odkriti medvojni spisi, ki so pokazali na de Manov antisemitizem. Podobno kot v drugih poglavjih avtor bolj znane dekonstruktiviste zoperstavi še kitajski in indijski literarni teoriji (v tem kontekstu pa ponuja zanimivo medkulturno branje del indijskega pesnika in dramatika Kālidāsa).

$\mathrm{V}$ nadaljevanju Damrosch obravnava vprašanje poliglotizma, ki predstavlja enega bistvenih vidikov naše vede. Znan je poziv in zahteva številnih oddelkov za primerjalno književnost po svetu, da mora vsak komparativist tekoče znati vsaj še dva ali tri tuje jezike. Da je za primerjanje literarnih tradicij potrebno znanje več jezikov, je teza, ki spremlja komparativistiko praktično od njenih začetkov. Damrosch se v sklopu razmisleka o poliglotizmu posveti razvoju tega koncepta, in sicer od poudarka na aktivnem znanju francoščine in nemščine $\mathrm{v}$ ameriški komparativistiki šestdestih let do utemeljitelja koncepta poliglotizma v komparativistiki Renéja Étiembla, pa do sodobnih prevodoslovnih teorij in vprašanja, ali lahko komparativist pravzaprav primerja več literarnih del v prevodu. Primerjanju preko prevodov je Damrosch, kot bodo dobro vedeli vsi, ki poznajo njegova ostala dela, precej naklonjen.

Še posebej bo slovenske bralce zanimalo šesto poglavje, v katerem avtor raziskuje različne koncepte književnosti in se sprašuje, kaj sploh je literatura. Razpravo otvori podpoglavje z naslovom "A Tale of Two Knjižnici» in se začne takole: "Dobra točka, kjer lahko začnemo, se nahaja v Ljubljani. Slovensko literarno izročilo je staro več 
stoletij in prestolnica ga hrani $\mathrm{v}$ dveh glavnih knjižnicah (knjižnici, iz slovanskega pojma za 'knjige')...«(209). Avtor razpravo nadaljuje z opisom Semeniške knjižnice ter NUK-a, nato pa se posveti poeziji Franceta Prešerna in vprašanju nacionalnega pomena tega pesnika. V prihodnosti bo zanimivo spremljati, kako močno bo Comparing the Literatures popularizirala slovensko književnost in Prešerna po svetu, $s$ čimer bo mogoče aktivno opazovali vlogo globalne akademske mreže, ki za kanonizacijo perifernih literarnih tradicij potrebuje prav takšne spodbude akademskih centrov. Nato avtor razpravlja še o kanonizaciji, majhnih ter perifernih literarnih tradicijah, globalnem literarnem trgu in podobno. Posebej je zanimiva razprava o odnosih med literaturo in drugimi mediji (predvsem videoigrami, sodobno umetnostjo in performansom), pri čemer avtor zagovarja tezo, da mora komparativistika te intermedialne fenomene vzeti resno in jih začeti natančno preučevati.

Zadnji dve poglavji sta posvečeni razpravi o svetovi književnost in o literarnih primerjavah. Glede svetovne književnosti Damrosch ponuja precej dolgo refleksijo najnovejših tematik in razprav, ki jih na zanimiv način preplete $\mathrm{z}$ različnimi literarnimi primeri iz svetovnega kanona (Calvino, Yourcenar, Marquéz, Kadare) ter popularne književnosti (J. R. R. Tolkien, Conan Doyle). Nato se posveti bistvenemu vprašanju komparativistike, torej vprašanju, kaj so literarne primerjave in kako primerjati literature. Pri tem se spopade z nekaterimi novejšimi razpravami v primerjalni književnosti (Pheng Cheah, Emily Apter, Haun Saussy, Natalie Melas, Rajagopalan Radhakrishnan) in v drugih vedah, ki se posvečajo vprašanju medkulturnega primerjanja (Sheldon Pollock, Marcel Detienne), odlično pa v razpravo vključuje tudi ne-Evropske akademske kontekste, na primer, delo kitajskih komparativistov Cao Shunqing in Zhang Longxi. Bralca, ki pozna Damroschevo raziskovanje, ne bo presenetilo, da se tudi v svoji najnovejši študiji zavzema za čim širše literarno primerjanje tako preko prostora (primerjave naj zajemajo čim več različnih kultur) kot časa (zajamejo naj čim daljše časovno obdobje), to tezo pa utemelji še z zanimivim poskusom primerjave literarnih modernizmov po svetu in $\mathrm{v}$ različnih časovnih obdobjih.

$\mathrm{V}$ zaključku, ki je naslovljen s pomenljivim naslovom »Rebirth of a Discipline", oblikovan kot odgovor na polemično študijo Gayatri Spivak The Death of the Discipline (2003), David Damrosch ponudi svoj pogled na prihodnost primerjalne književnosti. Njegova vizija je optimistična, prihodnost komparativistike pa vidi $\mathrm{v}$ pluralnosti sodobnih literarnovednih pristopov. $\mathrm{V}$ prvi vrsti te prepozna $\mathrm{v}$ bogati interdisciplinarni zasedenosti letnih konferenc Ameriške zveze za primerjalno književnost (ACLA), ki se odražajo tudi v nedavnem poro- 
čilu o stanju vede (»State of the discipline report»). Po drugi strani pa izpostavi interdisciplinarnost ter implementacijo novih literarnovednih pristopov v seriji najnovejših komparativističnih študij, ki po njegovem mnenju kažejo na revitalizacijo in svetlo prihodnost naše vede (npr. Edmon, Levy, Ungureanu, Venkat Mani, pa tudi Apter, Cheah, Friedman, Hitchcock, Gupta, Moser, Jay, Casanova, Ganguly, Feng, Bhattacharya in drugi).

Comparing the Literatures je po What is World Literature? najpomembnejša knjiga Davida Damroscha in bo v naslednjih letih gotovo močno zaznamovala sodobno komparativistiko. Harvardski komparativist predstavi optimističen odgovor na krizo, $v$ kateri se je primerjalna književnost nahajala nekje od osemdesetih let naprej. Odgovor išče in prepričljivo najde $\mathrm{v}$ sodobnejših komparativistični pristopih (postkolonialna teorija, vprašanja globalizacije, prevodoslovje, kulturna hibridnost, intermedialnost, svetovni literarni modernizmi...). Povedano drugače, prihodnost primerjalne književnosti je »svetovna primerjalna književnost «, veda, ki bo upoštevala in preučevala kulturno, historično, intermedialno in socialno večplastnost književnost in literarnih tradicij. A še bolj kot sama teza glede prihodnosti discipline je zanimiva Damrosceva argumentacija, ki ni usmerjena naprej v prihodnost, ampak nazaj v preteklost. Kot odlično pokaže avtor, je namreč zgodovina naše discipline še vedno precejšnja neznanka, a je mnogo bolj interkulturna, transnacionalna, interdisciplinarna ter politična, kot se zdi na prvi pogled. Morda za prepoznanje tega dejstva potrebujemo nekaj brskanja po preteklosti in je potrebno včasih usmeriti pogled stran od kanoniziranih komparativistov, a preteklost primerjalne književnost je vedno bila "svetovna«, torej takšna kot bo nedvomno tudi njena prihodnost.

1.19 Recenzija / Review

UDK 82.0

DOI: https://doi.org/10.3986/pkn.v44.i1.12 